\title{
The effect of a national mastitis control program on the attitudes, knowledge, and behavior of farmers in the Netherlands
}

\author{
J. Jansen, ${ }^{\star 1}{ }^{1}$ G. van Schaik, $†$ R. J. Renes, ${ }^{\star}$ and T. J. G. M. Lam†‡ \\ *Communication Science, Wageningen University, Wageningen, the Netherlands \\ †GD Animal Health Service Ltd., Deventer, the Netherlands \\ ‡Dutch Udder Health Centre (UGCN), Deventer, the Netherlands
}

\section{ABSTRACT}

Over the years, much effort has been put into implementing mastitis control programs in herds. To further improve utilization of such programs, there needs to be an understanding of the attitudes, knowledge, and behavior of farmers regarding udder health, and the way this can be influenced by mastitis control programs. This study aimed to explore the effect of a national mastitis control program on Dutch farmers' attitudes, knowledge, and behavior regarding mastitis. A total of 378 dairy farmers completed a survey on attitudes, knowledge, and behavior regarding mastitis before the start of a national mastitis control program in 2004, and 204 completed a similar survey in the final year of the program (2009). Although the average annual bulk milk somatic cell count (BMSCC) remained the same, the farmers' self-reported attitudes, knowledge, and behavior changed significantly. The problem level of BMSCC decreased from 285,000 cells/mL in 2004 to 271,000 cells $/ \mathrm{mL}$ in 2009 . More farmers perceived that they had sufficient knowledge about the prevention of mastitis (34\% in 2004 vs. $53 \%$ in 2009) and they more often perceived that they knew the cause of a mastitis problem (25\% in 2004 vs. $37 \%$ in 2009). The use of gloves for milking increased from 15 to $46 \%$, the use of a standardized mastitis treatment protocol increased from 7 to $34 \%$, and freestalls were cleaned more often (2.28 vs. 2.51 times/d) in 2009 compared with 2004 . Most changes in attitudes, knowledge, and behavior did not differ between groups of dairy farmers whose herds had an initially low $(\leq 162,000$ cells $/ \mathrm{mL})$, medium (163,000 to 205,000 cells $/ \mathrm{mL})$, or high $(>206,000$ cells/ $\mathrm{mL}$ ) BMSCC. The high BMSCC group significantly decreased their annual BMSCC level by 15,000 cells/ $\mathrm{mL}$. Regression analysis showed that the decrease in BMSCC was associated with a change in farmers' perceptions (e.g., increased perceived knowledge about the

Received April 6, 2010.

Accepted August 26, 2010.

${ }^{1}$ Corresponding author: jolanda.jansen@wur.nl effect of the milking machine on mastitis) and with a change in certain management practices (e.g., disinfecting all teats after milking). The results showed that a national mastitis control program affected the attitudes, knowledge, and behavior of farmers regarding mastitis and could contribute to udder health improvement in the long term.

Key words: mastitis control, management, communication, attitude

\section{INTRODUCTION}

Over the years, much effort has been put into the implementation of mastitis control programs in dairy herds. Evaluation of such extension education programs is necessary to optimize future campaigns (Chase et al., 2006). The aim of a mastitis control program is to improve management practices by influencing farmer behavior to reduce mastitis incidence and improve milk quality (Barkema et al., 1998, 1999; Jansen et al., 2009). When an attempt is made to influence people to change their behavior, many theories from social psychological sciences may be applied. One theory is the theory of planned behavior (Ajzen, 1991), which has been applied previously in agricultural research (Beedell and Rehman, 2000; Burton, 2004; Ellis-Iversen et al., 2010) and in behavioral interventions (Armitage and Conner, 2001; Hardeman et al., 2002). According to this theory, attitudes and knowledge (e.g., how do I feel about mastitis?), perceived social norms (e.g., how do others feel about mastitis?), and perceived behavioral control (e.g., can I do something about it?) influence behavioral intentions and actual behavior (e.g., to deal with mastitis prevention).

A study on Dutch dairy farmers' attitudes, knowledge, norms, perceived behavioral control, and behavior regarding mastitis showed that the variance in the farms' mastitis situation, measured in terms of bulk milk SCC (BMSCC) and clinical mastitis incidence, was associated with these behavioral determinants (Jansen et al., 2009). In particular, farmers' perceived norms on satisfaction and problem levels of mastitis, as well as their 
perceived control of mastitis, were positively associated with the real mastitis situation on their farms. These results corresponded to the theory of planned behavior. It can be suggested that to change farmers' behavior to improve udder health, behavioral determinants such as the attitudes, knowledge, norms, and perception of control of the farmers need to be changed. Consequently, it is necessary not only to study the biophysical outcomes to evaluate and to improve mastitis control programs, but also to evaluate the program-induced change in behavioral determinants, which may be influenced by the initial udder health situation.

This study aimed to determine whether farmers' attitudes, knowledge, norms, perception of control, and behavior changed over the course of a national udder health program; whether these changes differed between herds with different udder health situations at the start of the program; and whether these changes explained a decrease or an increase in BMSCC levels.

\section{MATERIALS AND METHODS}

\section{The Udder Health Program}

In 2005 , a project was initiated to improve udder health in the Netherlands: the 5-yr mastitis control program of the Dutch Udder Health Centre (UGCN, Deventer, the Netherlands). The communication strategies of the udder health project consisted of 2 main routes to reach as many farmers as possible: an extensive, direct multi-media approach using articles in farm magazines, campaigns to stimulate specific preventive measures, presentations at agricultural fairs, mailings to all dairy farmers; and an indirect approach through veterinarians as intermediaries between UGCN and farmers (Jansen et al., 2010). In 2008, 200 of 326 veterinary practices specializing in dairy cattle participated in the program serving about 17,000 dairy farmers (approximately $85 \%$ of all Dutch dairy farmers), of which 3,169 farmers (approximately 16\% of all Dutch dairy farmers) participated in on-farm study groups on udder health issues organized by their veterinarian.

\section{Participants}

Between April and July 2004, an extensive baseline survey was conducted on farmers' attitudes, knowledge, and behavior, in which 378 Dutch dairy farmers participated (response rate 69.6\%; Jansen et al., 2009). Criteria for participation were (1) an average farm size $>50$ cows, (2) age of the farmer $<57 \mathrm{yr}$, and (3) farms had to participate in the regular test-day recording, with test-day intervals of 3 to $6 \mathrm{wk}$. These criteria were used to ensure that the farms would be able to par- ticipate in the Dutch udder health program during the coming years. The BMSCC data collected every 2 wk from April 2004 to April 2005 were used to calculate the initial arithmetic mean annual BMSCC. After the baseline study was completed, the UGCN approach toward these farmers did not differ from its approach to other farmers in the country.

Between April and July 2009, the same farmers were asked to participate in a similar survey, resulting in a dataset of 207 dairy farmers that participated in both surveys. The BMSCC data for 2009 were used to calculate the 2009 average annual BMSCC. The reasons for 171 farmers not participating in the 2009 survey were as follows: (1) farmers did not have the time or the inclination to fill in the forms (24\%); (2) farmers could not be reached $(22 \%)$; (3) farmers perceived surveys as useless, not relevant, or had a bad experience when participating in other studies (21\%); (4) had quit farming $(9 \%)$; (5) personal circumstances $(9 \%)$; or (6) other reasons $(15 \%)$. The nonresponders did not differ from the responders with regard to their annual BMSCC in $2004(P=0.58)$. Nonresponders had less interest in mastitis treatment and prevention, were less interested in reading mastitis articles, had less contact with independent consultants and the Animal Health Service (Deventer, the Netherlands), and had a more negative opinion about the value of veterinary advice during the baseline survey in $2004(P<0.05)$.

\section{Questionnaire}

The data on attitudes, knowledge, and behavior were collected in 2004 and in 2009 using a structured questionnaire containing 50 items regarding behavior and farm demographics, and 72 items about farmers' attitudes, knowledge, and information sources (Jansen et al., 2009; Appendix). The attitude and behavior items were measured using binary variables, open questions, and statements that the farmers rated on a 5-point Likert scale according to how much they agreed or disagreed with the statements (Likert, 1932). When frequencies are presented in the results section, scores 1 (disagree) and 2 (partly disagree) are combined, as are scores 4 (partly agree) and 5 (agree).

\section{Statistical Analyses}

To compare answers between 2004 and 2009 in general, nonparametric Wilcoxon signed-rank tests $(P$ $\leq 0.05)$ were performed. In addition, for each survey variable, gain scores were calculated by subtracting the value in 2004 from the value in 2009. A positive gain score means an increased score on that question. To compare differences in gain scores between farmers 
with different BMSCC levels during the baseline survey, the herds were divided into 3 groups of equal size: the lowest, middle, and highest of the 12-mo average BMSCC levels. Consequently, the following threshold values were used: low BMSCC $(\leq 162,000$ cells $/ \mathrm{mL}, \mathrm{n}$ $=64)$, medium BMSCC $(>162,000$ and $\leq 205,000$ cells $/$ $\mathrm{mL}, \mathrm{n}=65)$, and high BMSCC $(>206,000$ cells $/ \mathrm{mL}, \mathrm{n}$ $=65)$. The BMSCC of 13 farms in 2004 were unknown; they were excluded from this part of the analysis.

To compare differences between the 3 groups regarding their change in attitudes, knowledge, and behavior over time, nonparametric Kruskal-Wallis analyses were performed using $P \leq 0.10$ as threshold value due to the small group sizes. Furthermore, Wilcoxon signedrank tests $(P \leq 0.05)$ were performed to determine whether the gain scores within a group deviated from zero. These results were compared with the overall gain score without segmentation of groups to see whether some variables did not change between 2004 and 2009, but did change within certain groups.

To explain the changes in annual BMSCC between 2004 and 2009 by changes in attitudes, knowledge, and behavior, a stepwise linear regression analysis was performed. In this regression analysis, the gain score of BMSCC was used as a dependent variable, and all the gain scores of the 122 survey variables (Appendix) were used as independent variables. The initial BMSCC at the baseline survey was forced into the regression model as a continuous variable, as it was assumed that it was easier to considerably decrease BMSCC from initially high BMSCC levels than from initially low levels. An automated forward and reverse stepwise regression procedure was used, with $P<0.05$. The gain score on BMSCC was assumed normally distributed, as Kolmogorov-Smirnov $(P>0.200)$ and Shapiro-Wilk $(P$ $>0.901)$ tests showed nonsignificant results.

The final regression model was checked for normality and multicollinearity using the Durban Watson test for independent errors, the average variance inflation factor, tolerance levels, Cook's distance, and test of normality of the standardized residuals (KolmogorovSmirnov, $\mathrm{P}-\mathrm{P}$ and $\mathrm{Q}-\mathrm{Q}$ plot and histogram). All data were analyzed using SPSS (SPSS 15.0.1 for Windows, SPSS Inc., Chicago, IL).

\section{RESULTS}

\section{Overall Differences Between 2004 and 2009}

In general, the results showed that the mean annual BMSCC of the baseline survey in $2004(187,000$ cells $/ \mathrm{mL}$ ) did not change compared with that in 2009 (194,000 cells $/ \mathrm{mL} ; P=0.20)$. Yet, compared with 2004, aspects of attitudes, knowledge, behavior, and the type of information sources used did change $(P \leq 0.05$; Table $1)$. During that period, farmers increased the number of milking cows (78 vs. 88 cows), whereas the total workforce per herd stayed the same, at approximately 1.65 full-time equivalents. This change manifested itself in the attitude towards mastitis. Extra work was more often perceived as the most annoying aspect of mastitis (26 vs. $49 \%$ ), and more farmers stated that it was important to keep farm management simple (79 vs. $88 \%$ ). With regard to farmer norms, their problem level of BMSCC changed; farmers perceived a problem at 285,000 cells/mL in 2004 compared with 271,000 cells/ $\mathrm{mL}$ in 2009. Suggestions from farmers to the researchers on how to decrease the national BMSCC changed between the baseline and the end survey. More farmers mentioned that they would prefer a bonus for a low BMSCC (71 vs. 86\%), and fewer farmers stated that they would prefer an increase in fines (19 vs. 11\%).

In the 2009 survey, farmers perceived that they had more knowledge about controlling mastitis problems than in 2004 (34 vs. 53\%), and they stated that they more often knew the causes when a mastitis problem occurred (25 vs. 37\%). Compared with 2004, more farmers claimed to have sufficient knowledge about the influence of nutrition on mastitis (24 vs. 29\%), and more claimed to know that they had to focus on the hygiene of milking procedures when Staphylococcus aureus problems occurred (76 vs. $84 \%$ ).

With regard to information sources, farmers reported using the Internet more often ( 8 vs. $25 \%$ ), whereas the importance of other information sources, such as the veterinarian, remained stable. Information sources such as farm magazines, independent consultants, and the Dutch GD Animal Health Service decreased in importance.

With regard to behavior, more farmers stated they would delay treatment of cows with subclinical mastitis if there were problems filling the milk quota (18 vs. $34 \%$ ). The use of a herd-specific mastitis treatment protocol increased from 7 to $34 \%$, and farmers began to use udder health traits more often when selecting bulls (46 vs. $61 \%$ ). Freestalls were cleaned more often (2.28 vs. 2.51 times/d), and more farmers used blanket dry-cow therapy with antibiotics ( 85 vs. $94 \%$ ). The use of milking gloves increased from 15 to $46 \%$. Cleaning the udder before milking with a dry cloth decreased (39 vs. 31\%), as did the percentage of farmers who prevented cows from lying down after milking (56 vs. $46 \%$ ). The percentage of farmers who engaged in foremilk stripping on all cows also decreased (33 vs. 27\%). Automatic measurements of milk quality by the milking machine were more often used to diagnose clinical (4 vs. 13\%) and subclinical (4 vs. $10 \%$ ) mastitis. Fewer farmers considered observation of the cow and the udder as a good way to diagnose 
Table 1. Changes $(P \leq 0.05)$ in dairy farmers' attitudes, knowledge, behavior, and use of information sources between 2004 and 2009 in a Dutch national mastitis control program $(\mathrm{n}=207)^{1}$

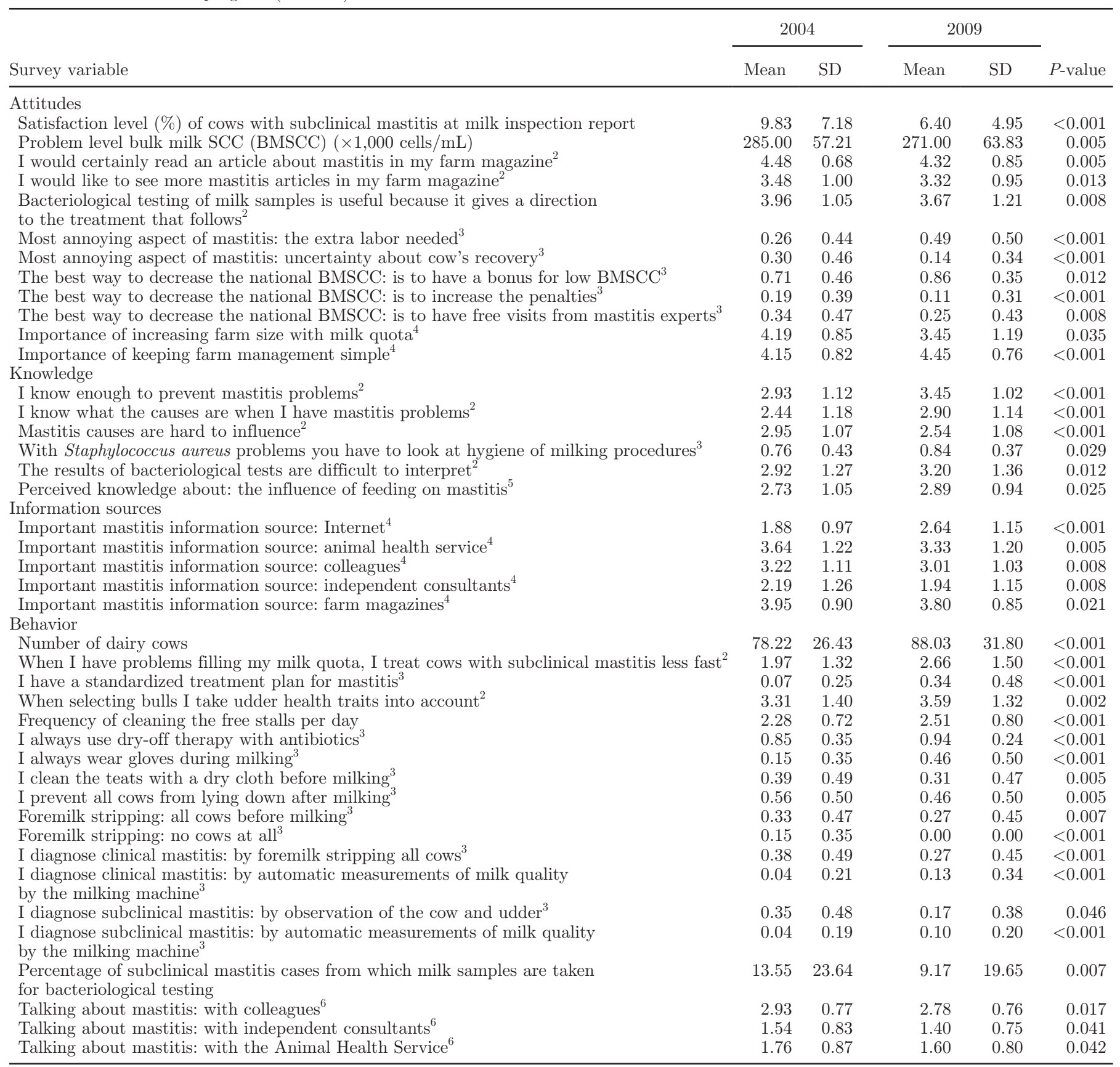

${ }^{1}$ Results of Wilcoxon signed-rank tests to compare farmers' response in 2004 and 2009.

${ }^{2}$ Scored from 1 (disagree) to 5 (agree).

${ }^{3}$ Binary variable: $0=$ no, $1=$ yes.

${ }^{4}$ Scored from 1 (not important) to 5 (very important).

${ }^{5}$ Scored from 1 (poor) to 5 (excellent).

${ }^{6}$ Scored from 1 (never) to 5 (very often).

subclinical mastitis (35 vs. 17\%) and fewer farmers used bacteriological testing of milk samples from subclinical mastitis cases (14 vs. 9\%). Talking about mastitis with the veterinarian, study group members, the accountant, and the nutritional consultant did not change compared with 2004, but mastitis was less often discussed with colleagues, independent consultants, and the Animal Health Service in 2009. 
Table 2. Significant $(P \leq 0.10)$ differences between groups of low, medium, and high bulk milk SCC (BMSCC) farmers and their change in BMSCC, attitudes, knowledge, and behavior measured in 2004 and 2009 in a Dutch national mastitis control program $(\mathrm{n}=191)^{1}$

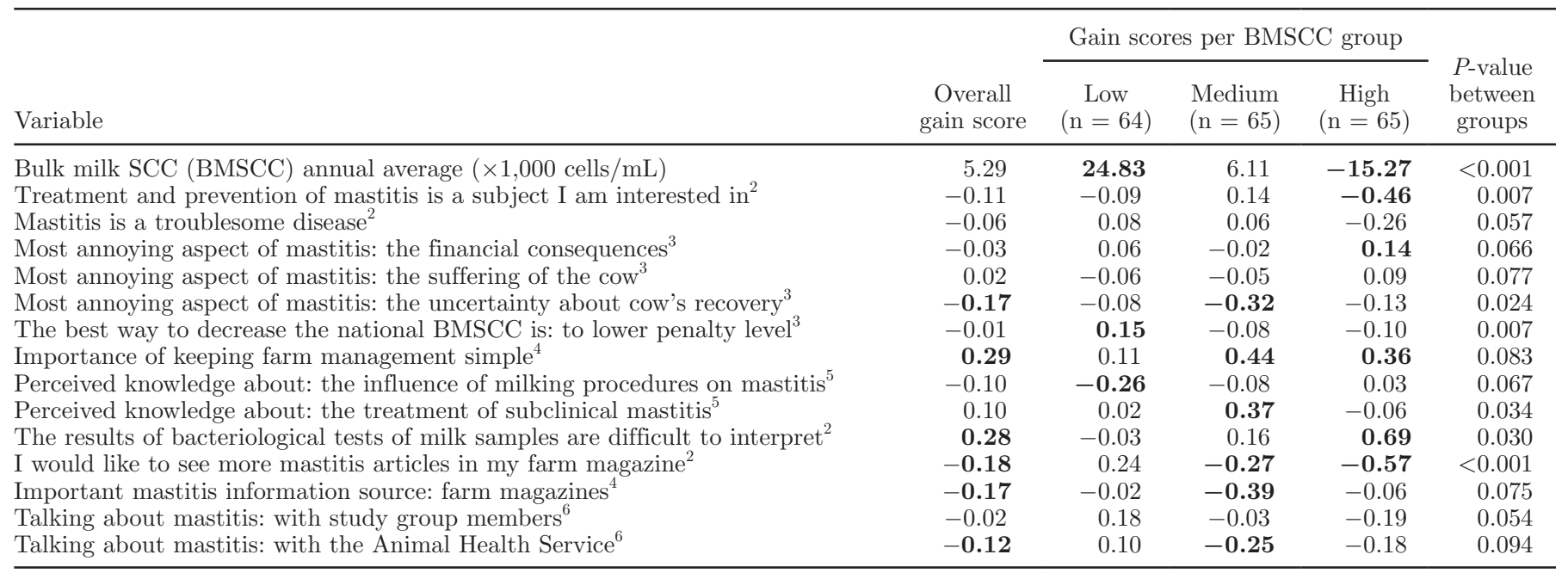

${ }^{1}$ Results of Kruskal-Wallis analyses $(P \leq 0.10)$ comparing gain scores calculated as $2009-2004$ between groups with a low $(\leq 162,000)$, medium $(163,000-205,000)$, or high $(>206,000)$ average annual BMSCC starting April 2004. Values in bold are gain scores within a group that are different from zero (Wilcoxon signed-rank test $P \leq 0.05$ ).

${ }^{2}$ Scored from 1 (disagree) to 5 (agree).

${ }^{3}$ Binary variable: $0=$ no, $1=$ yes.

${ }^{4}$ Scored from 1 (not important) to 5 (very important).

${ }^{5}$ Scored from 1 (poor) to 5 (excellent).

${ }^{6}$ Scored from 1 (never) to 5 (very often).

\section{Comparing Low, Medium, and High BMSCC Groups}

Table 2 shows 3 types of results. First, it shows the survey variables that differed between low, medium, and high initial BMSCC groups, using Kruskal-Wallis analyses with a threshold value of $P<0.10$. Second, it shows the gain scores of these variables; bold scores indicate gain scores that were different from zero within the group $(P \leq 0.05)$. Third, the table shows the average overall gain score between 2004 and 2009 without group segmentation, and the bold scores indicate gain scores that were different from zero $(P \leq 0.05)$. Of the 122 variables in the survey, 15 were different for farmers with a different initial BMSCC level (Table 2). Comparison of Table 1 and Table 2 shows that most overall changes in attitudes, knowledge, and behavior applied to all farmers, regardless of their initial BMSCC level, because no significant differences could be found between groups regarding their gain scores on behavior and on problem and satisfaction levels of mastitis.

In contrast with the overall mean gain score, the annual BMSCC of the low BMSCC farmers increased significantly $(134,000$ vs. 158,000 cells/mL), the BMSCC of the medium BMSCC farmers maintained the same level (185,000 vs. 192,000 cells/mL), and the BMSCC of the high BMSCC farmers decreased significantly (243,000 vs. 228,000 cells $/ \mathrm{mL}$ ).
The high BMSCC group differed from the low group because the gain scores of the high group showed a decrease in interest in mastitis issues between 2004 and 2009. For the high BMSCC group, the financial consequences of mastitis became more annoying, and the results of bacteriological culturing of milk samples were perceived as more difficult to interpret. The medium BMSCC group differed from the low and the high groups regarding their decreased use of information sources such as farm magazines and the Animal Health Service. The medium BMSCC group perceived increased knowledge on treatment of subclinical mastitis and was more confident about the recovery of a mastitis cow. The low BMSCC farmers perceived decreased knowledge on mastitis and milking procedures and became more interested in mastitis information and contact with others about mastitis than did the farmers in the medium and high BMSCC groups.

\section{Factors Associated with an Increase or Decrease in BMSCC}

A regression analysis was performed to study factors that were associated with an increase or decrease in BMSCC levels on individual farms. The average gain score of BMSCC was 5,290 cells/mL, ranging from a decrease of 140,130 cells $/ \mathrm{mL}$ to an increase of 168,170 
Table 3. Change of annual bulk milk SCC (BMSCC) between 2004 and 2009 explained by a change in attitudes, knowledge, and behavior between 2004 and 2009

\begin{tabular}{|c|c|c|c|c|c|}
\hline Variables included in model & Mean & SD & \multicolumn{3}{|c|}{ Stepwise linear regression analysis } \\
\hline BMSCC annual average baseline survey $2004(\times 1,000$ cells $/ \mathrm{mL})$ & 187.000 & 49.30 & -0.37 & -5.13 & $<0.001$ \\
\hline The best way to decrease the national BMSCC: is to increase the penalties ${ }^{2,4}$ & -0.09 & 0.45 & -0.21 & -3.02 & 0.003 \\
\hline Perceived knowledge about: the influence of the milking machine on mastitis ${ }^{2,5}$ & -0.10 & 0.76 & -0.36 & -4.53 & $<0.001$ \\
\hline Perceived knowledge about: the influence of milking procedures on mastitis ${ }^{2,5}$ & -0.09 & 0.83 & 0.20 & 2.45 & 0.016 \\
\hline $\begin{array}{l}\text { The first thing I do when a cow has a high cell count is: } \\
\text { to treat directly with antibiotics }{ }^{2,4}\end{array}$ & 0.03 & 0.37 & -0.22 & -3.17 & 0.002 \\
\hline Foremilk stripping: no cows at all ${ }^{2,4}$ & -0.14 & 0.35 & -0.22 & -2.97 & 0.004 \\
\hline Foremilk stripping: only when I perceive mastitis problems ${ }^{2,4}$ & -0.03 & 0.30 & -0.17 & -2.36 & 0.020 \\
\hline
\end{tabular}

${ }^{1}$ Coefficients are standardized regression weights (betas). Model $F=10.49(P<0.001)$, $\mathrm{df}=10 ; 117, \mathrm{R}^{2}=0.50$, adjusted $\mathrm{R}^{2}=0.45$.

${ }^{2}$ Values of these variables are calculated gain scores (calculated as value 2009 - value 2004).

${ }^{3}$ Scored from 1 (disagree) to 5 (agree).

${ }^{4}$ Binary variable: $0=$ no, $1=$ yes.

${ }^{5}$ Scored from 1 (poor) to 5 (excellent).

cells/mL. As indicated in Table 3 , the results of the stepwise linear regression analysis showed that the changes in attitudes, knowledge, and behavior explained $45 \%$ of the variation in the change in BMSCC levels. Initial BMSCC was an important predictor for this variation; the higher the initial BMSCC level, the lower the gain score on BMSCC. In other words, a high initial BMSCC seems to be associated with a decrease in BMSCC over the years.

Some changes in attitudes were associated with a change in BMSCC. Farmers who perceived bacteriological testing as more expensive over the years were associated with an increase in BMSCC levels. Farmers who became more positive about increased penalties for BMSCC were associated with a decrease in BMSCC. In addition, a perceived change in knowledge was associated with a change in BMSCC. Farmers who perceived an increase in knowledge on the effect of the milking machine on mastitis were associated with a decrease in BMSCC; however, a perceived increase in knowledge on the effect of milking on mastitis was associated with an increase in BMSCC levels.

Finally, changes in behavior were associated with a change in BMSCC. Farmers who started disinfecting all teats after milking and who began to treat subclinical mastitis cases immediately after diagnosing them were associated with a reduction in BMSCC. In addition, farmers who started to strip foremilk when mastitis problems occurred were associated with a reduction in BMSCC levels.

The model was checked for normality and multicollinearity: the Durban Watson test for independent errors was 2.0, the average variance inflation factor was 1.1 , and the average Cook's distance was 0.02 , with all values $<1.0$. The standardized residuals were tested using Kolmogorov-Smirnov $(P>0.20)$, and the $\mathrm{Q}-\mathrm{Q}$ plot and histogram of the standardized residuals gave no reasons for concern. Removing influential cases did not influence the model fit. Consequently, the model fit of the regression analysis was good.

\section{DISCUSSION}

\section{The Relationship Between Perceptions and Mastitis}

The results of this study show that perceptions changed during the course of the mastitis control program. In particular, the attitude of farmers toward problem and satisfaction levels of BMSCC changed favorably. This is important because these normative values were associated with actual BMSCC and were expected to influence the udder health status in the long term (Jansen et al., 2009). The results show that perceived behavioral control or self-efficacy regarding mastitis increased. In other studies, self-efficacy was a useful predictor of both behavioral intentions and behavior (Armitage and Conner, 1999, 2001). Therefore, it was assumed that farmers perceived that they were better able to deal with mastitis problems in 2009 than in 2004; this consequently could influence their future response to mastitis problems. In line with that, some important management practices that are associated with mastitis control, such as increased hygiene by cleaning the freestalls more frequently, increased use of gloves during milking, increased use of a proper dry-off therapy, and increased selection of sires based on udder health measures, changed during the course of the control program. These changes in behavior did not differ 
between farmers with different initial BMSCC before the start of the program. The efforts of the control program seemed to reach all farmers, regardless of their initial udder health situation.

The behavioral changes measured did not seem to directly affect the average BMSCC status of the farms. This does not mean that BMSCC was not influenced. The results showed that farmers with an initially high BMSCC decreased their BMSCC considerably. The results provide few clues for the cause of these changes. Either the BMSCC changed due to management practices that were not measured in this survey or the variation among farmers in their attitude and behavioral changes was too high to determine specific factors that account for most of the decrease in BMSSCC. Moreover, it should be taken into account that the associations found in this study do not necessarily represent causal relationships. For example, the high BMSCC group decreased their BMSCC, but was also less interested in mastitis treatment and prevention. It can be assumed that because they were successful in decreasing their BMSCC and the problem was solved, they became less interested. It could also be argued that these changes were caused by regression toward the mean. However, the regression analyses show that a decrease in BMSCC was associated with a change in both perceptions and behavior of farmers.

It is likely that farmers who changed their perceptions and behavior but did not have a lower BMSCC by the end of the study may improve udder health in the long term. It should be taken into account that mastitis is a complex disease and cannot be easily solved in the short term by changing a single management factor; it requires a long-term change in general herd management (Barkema et al., 1999; LeBlanc et al., 2006).

\section{The Influence of External Factors}

Changes in farm management entail a long-term process and depend on contextual factors (Leeuwis, 2004) such as milk price, quota regulations, or infectious disease outbreaks. In this study, $45 \%$ of the variation in the decrease or increase in BMSCC could be explained by the survey variables. This result supported a study on explained variance in BMSCC levels (Jansen et al., 2009). This still means that $55 \%$ of the variance in BMSCC change could not be explained by the survey variables. It is important to note that although the survey was extensive and developed with mastitis experts, the total dataset of farmers' attitudes and behavior regarding mastitis could be incomplete; this could explain why the survey was not able to explain more than $50 \%$ of the variance in mastitis incidence (Jansen et al., 2009).
This study design has its limitations: the studied population was a random sample among younger farmers with larger herds. This approach was specifically adopted to include all farmers who were expected to continue farming in the future and contributed to milk quality in the Netherlands. Additionally, all farms participated in recording of herd composite SCC every 3 to $6 \mathrm{wk}$, whereas farmers that use other intervals or no testing for composite SCC do exist in the Netherlands. The results of this study may not apply to the entire Dutch dairy sector. In addition, the farmers participating could be different from the average Dutch farmers, because they were willing to participate (selection bias).

It is important to note that this study was based on self-reported attitudinal issues and behavior of farmers. It is possible that socially desirable answers were reported by the farmers, which could have led to a bias in the results. As the questions in both surveys were phrased in exactly the same way, it could be assumed that the degree of socially desirable answers, as well as the possible misinterpretation of questions, was comparable between the surveys. Although it is known that the repeatability of self-reported answers varies and that questions about management have generally a higher repeatability than questions about attitudes (Dufour et al., 2010), the results do suggest a difference between 2004 and 2009 .

During the 5 yr of the program, external factors such as fluctuating milk prices and uncertainty about quota regulations probably influenced farmers' behavior. Milk quota utilization is an important factor in decisionmaking concerning treatment of mastitis (Vaarst et al., 2002). The results show that farmers waited longer to treat subclinical mastitis cows when they had problems filling their milk quota, and this could have influenced their BMSCC status. Moreover, the results show that herds increased in size and that labor efficiency became more important during the course of the program. These factors may lead to an increase in BMSCC because less time may be available to apply mastitis control practices. The need for timesaving management practices could explain why certain management measures increased, such as the increased reliance on automatic measurements during milking, or decreased, such as fore stripping all cows before milking. Other external factors such as the weather or infectious diseases can also influence the BMSCC of herds, as evidenced by the blue tongue virus that emerged in the Netherlands in 2006 (Elbers et al., 2009).

\section{The Role of the National Mastitis Control Program}

It is debatable whether the changes in perceptions and behavior were caused by the national mastitis con- 
trol program, because the results cannot be compared to a control group of farmers who were not affected by the program. Yet, studies on activities within this national mastitis control program using different study populations showed a profound campaign effect on the behavior of farmers regarding, for example, the use of gloves during milking (Jansen et al., 2010). Evaluations of national programs should take into account that campaigns that aim to change behavior have small to moderate effects (Noar, 2006) and that a campaign goal to change $20 \%$ of a population's behavior would probably result in failure (Snyder et al., 2004). In this study, some management practices of farmers changed by more than $20 \%$ between both surveys, indicating a strong effect. In general, a campaign is considered successful when attitudes and beliefs are affected (Snyder et al., 2004; Noar, 2006) because the first step in behavioral change is a change in behavioral determinants such as perceived attitudes, knowledge, norms, and selfefficacy. At the start of the mastitis control program, an ongoing increase in national BMSCC levels occurred. During 5 yr, the overall mean BMSCC did not increase, suggesting that benefits may be attributed to the efforts of the control program, but long-term trends need further investigation to support this hypothesis. This study has shown that a mastitis control program is an important first step towards better udder health.

\section{CONCLUSIONS}

The results show that a national mastitis control program can be successful in changing attitudes, knowledge, and behavior regarding mastitis. Although the overall results suggest no general decrease in BMSCC in the 5-yr period, they do propose an association between a change in BMSCC on individual farms and a change in attitudes, knowledge, and behavior. Although more research is needed to identify the long-term effect of these changes, this study can contribute to an increased understanding of the effects of animal health programs.

\section{ACKNOWLEDGMENTS}

This study is part of the 5-yr mastitis program of the Dutch Udder Health Centre, Deventer, the Netherlands, and was financially supported by the Dutch Dairy Board, Zoetermeer, the Netherlands. The authors acknowledge the dairy farmers for their participation in these studies.

\section{REFERENCES}

Ajzen, I. 1991. The theory of planned behavior. Organ. Behav. Hum. Dec. 50:179-211.
Armitage, C. J., and M. Conner. 1999. The theory of planned behaviour: Assessment of predictive validity and 'perceived control'. Br. J. Soc. Psychol. 38:35-54.

Armitage, C. J., and M. Conner. 2001. Efficacy of the theory of planned behaviour: A meta-analytic review. Br. J. Soc. Psychol. 40:471-499.

Barkema, H. W., Y. H. Schukken, T. J. G. M. Lam, M. L. Beiboer, G. Benedictus, and A. Brand. 1998. Management practices associated with low, medium and high somatic cell counts in bulk milk. J. Dairy Sci. 81:1917-1927.

Barkema, H. W., J. D. Van der Ploeg, Y. H. Schukken, T. J. G. M. Lam, G. Benedictus, and A. Brand. 1999. Management style and its association with bulk milk somatic cell count and incidence rate of clinical mastitis. J. Dairy Sci. 82:1655-1663.

Beedell, J., and T. Rehman. 2000. Using social-psychology models to understand farmers' conservation behaviour. J. Rural Stud. $16: 117-127$.

Burton, R. J. F. 2004. Reconceptualising the 'behavioural approach' in agricultural studies: A socio-psychological perspective. J. Rural Stud. 20:359-371.

Chase, L. E., O. L. Ely, and M. F. Hutjens. 2006. Major advances in extension education programs in dairy production. J. Dairy Sci. 89:1147-1154.

Dufour, S., H. W. Barkema, L. DesCôteaux, T. J. DeVries, I. R. Dohoo, K. Reyher, J. P. Roy, and D. T. Scholl. 2010. Development and validation of a bilingual questionnaire for measuring udder health related management practices on dairy farms. Prev. Vet. Med. 95:74-85.

Elbers, A. R. W., A. N. van der Spek, and P. A. van Rijn. 2009. Epidemiologic characteristics of blue tongue virus serotype 8 laboratoryconfirmed outbreaks in The Netherlands in 2007 and a comparison with the situation in 2006. Prev. Vet. Med. 92:1-8.

Ellis-Iversen, J., A. J. C. Cook, E. Watson, M. Nielen, L. Larkin, M. Wooldridge, and H. Hogeveen. 2010. Perceptions, circumstances and motivators that influence implementation of zoonotic control programs on cattle farms. Prev. Vet. Med. 93:276-285.

Hardeman, W., M. Johnston, D. W. Johnston, D. Bonetti, N. J. Wareham, and A. Kinmonth. 2002. Application of the theory of planned behaviour in behaviour change interventions: A systematic review. Psychol. Health 17:123-158.

Jansen, J., R. J. Renes, and T. J. G. M. Lam. 2010. Evaluation of two communication strategies to improve udder health management. J. Dairy Sci. 93:604-612.

Jansen, J., B. H. P. Van den Borne, R. J. Renes, G. Van Schaik, T. J. G. M. Lam, and C. Leeuwis. 2009. Explaining mastitis incidence in Dutch dairy farming: The influence of farmers' attitudes and behaviour. Prev. Vet. Med. 92:210-223.

LeBlanc, S. J., K. D. Lissemore, D. F. Kelton, T. F. Duffield, and K. E. Leslie. 2006. Major advances in disease prevention in dairy cattle. J. Dairy Sci. 89:1267-1279.

Leeuwis, C. 2004. Communication for Rural Innovation. Rethinking Agricultural Extension. 3rd ed. Blackwell Science Ltd., Oxford, UK.

Likert, R. 1932. A technique for the measurement of attitudes. Arch. Psychol. 140:1-55.

Noar, S. M. 2006. A 10-year retrospective of research in health mass media campaigns: Where do we go from here? J. Health Commun. 11:21-42.

Snyder, L. B., M. A. Hamilton, E. W. Mitchell, J. Kiwanuka-Tondo, F. Fleming-Milici, and D. Proctor. 2004. A meta-analysis of the effect of mediated health communication campaigns on behavior change in the United States. J. Health Commun. 9:71-96.

Vaarst, M., B. Paarup-Laursen, H. Houe, C. Fossing, and H. J. Andersen. 2002. Farmers' choice of medical treatment of mastitis in Danish dairy herds based on qualitative research interviews. J. Dairy Sci. 85:992-1001. 


\section{Appendix}

Table A1. Survey variables of a questionnaire on attitudes, knowledge, behavior, and the use of information sources measured in 2004 (Jansen et al., 2009; reproduced with permission) and 2009 in a Dutch national mastitis control program $(\mathrm{n}=207)^{1}$

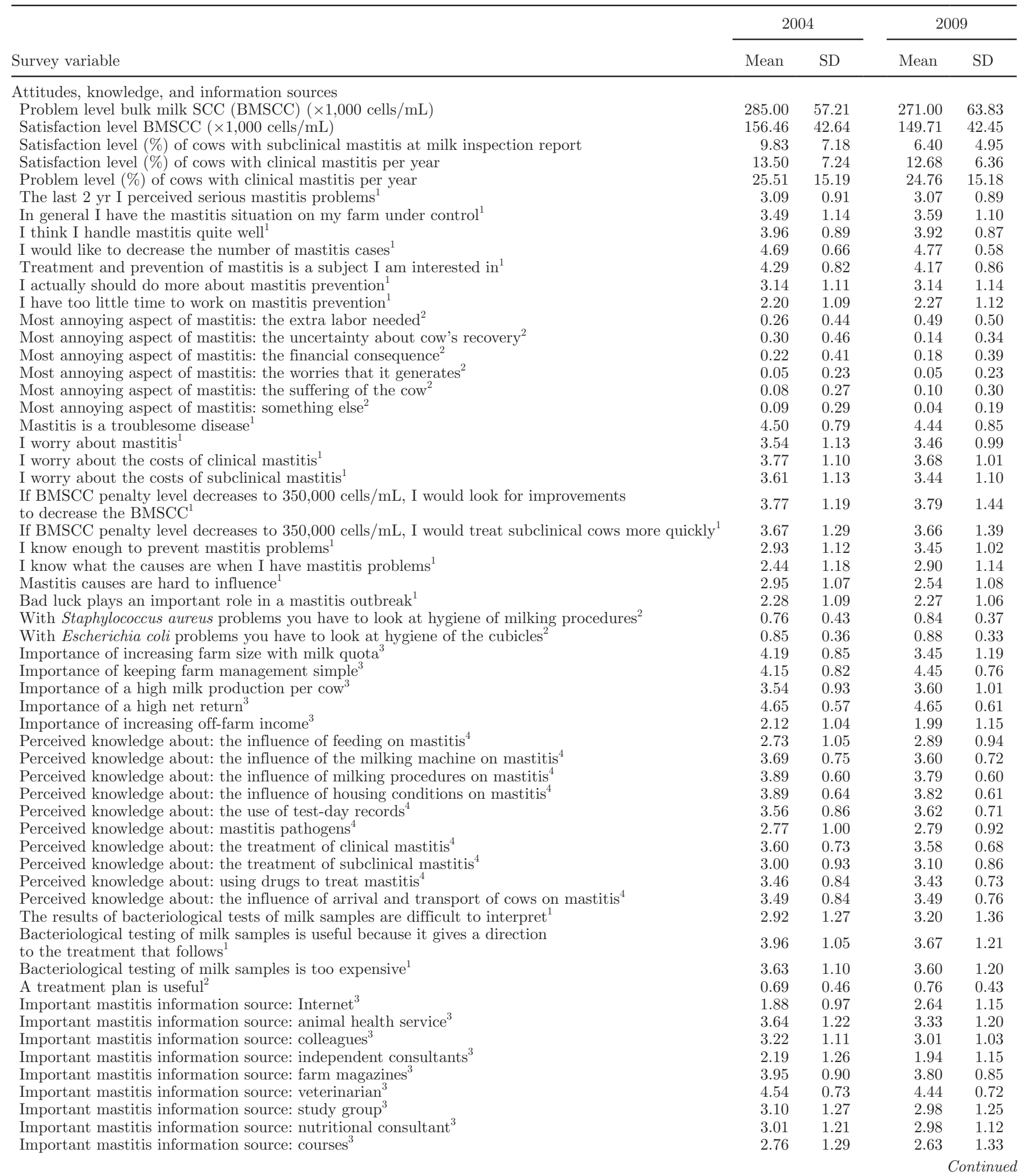


Table A1 (Continued). Survey variables of a questionnaire on attitudes, knowledge, behavior, and the use of information sources measured in 2004 (Jansen et al., 2009; reproduced with permission) and 2009 in a Dutch national mastitis control program $(\mathrm{n}=207)^{1}$

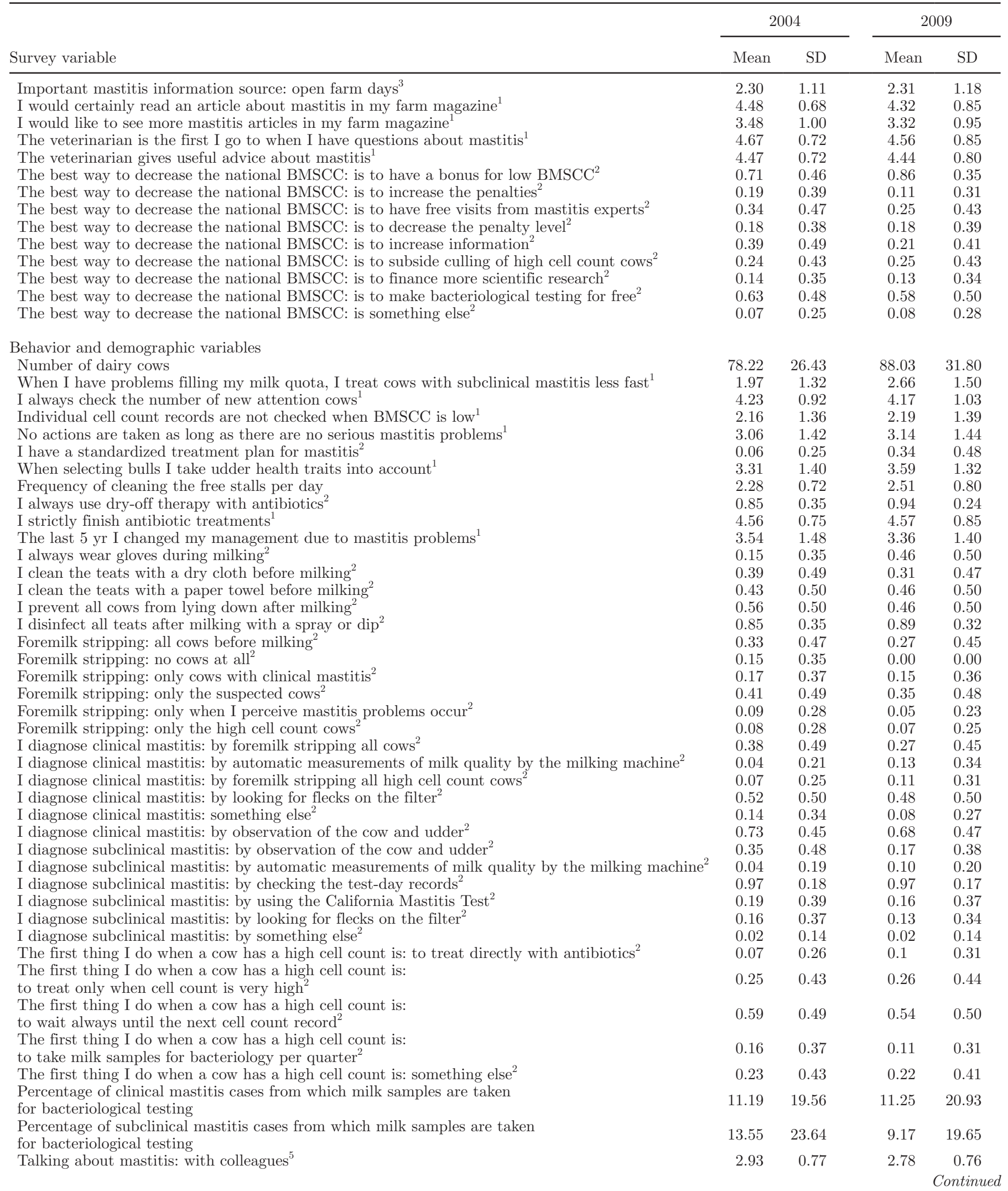


Table A1 (Continued). Survey variables of a questionnaire on attitudes, knowledge, behavior, and the use of information sources measured in 2004 (Jansen et al., 2009; reproduced with permission) and 2009 in a Dutch national mastitis control program $(\mathrm{n}=207)^{1}$

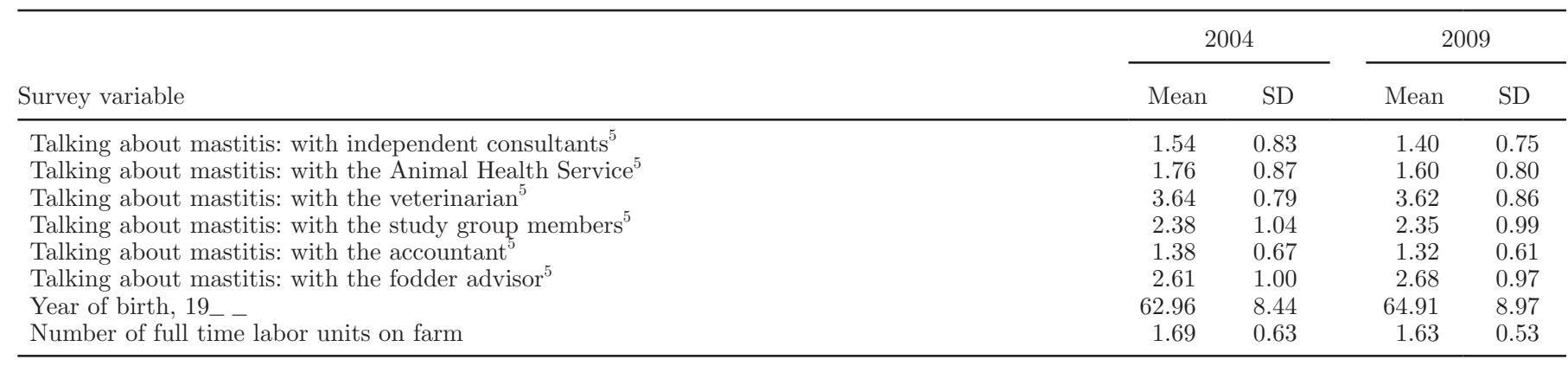

${ }^{1}$ Scored from 1 (disagree) to 5 (agree).

${ }^{2}$ Binary variable: $0=$ no, $1=$ yes.

${ }^{3}$ Scored from 1 (not important) to 5 (very important).

${ }^{4}$ Scored from 1 (poor) to 5 (excellent).

${ }^{5}$ Scored from 1 (never) to 5 (very often). 